\title{
Media authenticity and authority in Mauritius: On the mediality of language in religion
}

\author{
Patrick Eisenlohr \\ Utrecht University, Department of Cultural Anthropology, Heidelberglaan 2, PO Box 80140, 3508 TC Utrecht, The Netherlands
}

\section{A R T I C L E I N F O}

\section{Article history:}

Available online 5 April 2011

\section{Keywords:}

Language and mediation

Sound reproduction

Islam

Poetry

Indexicality

Mauritius

\begin{abstract}
A B S T R A C T
In this article I suggest that the rapidly growing interest in the intersection of linguistic anthropology and media needs to be accompanied by a deeper investigation of the mediality of language. Discussing Mauritian Muslims' uses of sound reproduction in religious events revolving around the recitation of devotional poetry, this paper explores how language as a medium converges and interacts with media technologies of other kinds. I suggest that the oscillation between a foregrounding of the medium and its phenomenological withdrawal characterizes the functioning of both linguistic mediation and other media technologies and provides a comparative dimension to examine their interplay.
\end{abstract}

(c) 2011 Elsevier Ltd. All rights reserved.

\section{Introduction}

The intersection of linguistic and media practices has become an increasingly important topic in linguistic anthropology, such as in the analysis of transformation of publics through uses of new media technology (Barker, 2008; Spitulnik, 1996), the regimentation of time and space in mass-mediated discourse (Agha, 2007), the spread of new forms of enregisterment of personality through television (Goebel, 2008), or the migration of strategies of voice representation from oral discourse to written online interaction (Jones and Schieffelin, 2009). These studies show that linguistic anthropological theories and methods are uniquely suited to an analysis of contemporary media practices, especially in investigating how precisely new media enable new forms of interaction and social and political organization, and how they otherwise become integrated into existing traditions and established contexts of interaction with their cultural contexts and ideological shapes. Nevertheless, linguistic anthropological work on media has stopped short of exploring what may perhaps be the strongest contribution linguistic anthropologists could make to anthropological engagements with contemporary media. In my view this is the systematic comparison of language as a medium of sociocultural processes with the ways various contemporary media technologies are recognized to similarly mediate and shape such processes. This question is important because for anthropologists media wield enormous power. In this paper I suggest that the rapidly growing interest in the intersection of linguistic anthropology and media needs to be accompanied by a deeper investigation of the mediality of language, and how this medial quality of language converges and interacts with media technologies of other kinds, such as contemporary audiovisual media and the internet.

\section{Mediation and media technology}

For quite a while it has become commonplace for anthropologists to assert that uses of media technologies such as print, audiovisual technologies, sound reproduction, or the internet do not just convey and channel socially and culturally situated action, but in fact crucially shape and even produce, or at least co-produce sociocultural formations and processes. Whether

E-mail address: p.eisenlohr@uu.nl 
the topic is nationalism, the public sphere, globalization, the so-called "turn to religion," or transnational connections of various kinds, anthropologists have highlighted the productive role of media practices in the emergence of these processes. Anthropologists have certainly rejected the tendencies towards technodeterminism that can be found in the work of some prominent exponents of media studies (Kittler, 1997; Virilio, 1998), but seem otherwise firmly wedded to positions of media constructionism and media generativism. There is however, a difficulty with this position. How can the commonly observed role of media as cultural and political creators be reconciled with the also frequently attested phenomenological disappearance of the medium when it is working properly? Whether it is being immersed in a book, making a phone call, watching a movie of surfing the internet, for its habitual users, the same media technologies that seem to co-produce, shape and create such forms of interaction also recede into the background to the point of vanishing almost entirely from the perspective of its users. How can the disappearing and thus seemingly transparent medium also at the same time be the powerful creator of socio-cultural worlds?

If one abandons the simple transmitter model of media, there is perhaps one key characteristic that unites the manifold objects and technologies that have been designated "media." This is their oscillation between highly obvious, visible and creative roles on one hand, and their tendency to vanish in the act of mediation on the other hand. This observation can be traced back to Aristotle's discussion of media diaphana, or transparent media which enable processes of perception by inhabiting the space between observer and object (Hoffmann, 2002, pp. 30-35). In the example of air, this medium ever only becomes a focus of attention if it does not operate normally, and disturbs vision or disables hearing. In fact, contemporary media theorists treat this double aspect of media as a fundamental of media technologies, as they swing back and forth between the modes of high visibility and salience Jay Bolter and Richard Grusin term "hypermediacy," and "immediacy" or self-erasure (Bolter and Grusin, 1999). Analyzing the relations between these two poles in, for example, contemporary digital technologies, Bolter and Grusin point out that "our two contradictory logics not only coexist in digital media today but are mutually dependent. Immediacy depends on hypermediacy” (Bolter and Grusin, 1999, p. 6). While media studies takes much of its intellectual energy from the insight that media have a profoundly shaping impact on human relations, summed up in the dictum that the "medium is the message" (McLuhan, 1964), newer forms of media also enable a "time-space compression" (Harvey, 1989, see also Tomlinson, 1999) to such a degree that the presence of the other in interactions is rendered so "real" that the medium seems to vanish into the background. As recent anthropological work on media has stressed, such denials of mediation enabled by seemingly "vanishing mediators" (Sterne, 2003) may even emerge as important sources of political power and legitimacy in a "politics of immediation" (Mazzarella, 2006; Allen, 2009; Eisenlohr, 2009). On the other hand, there is also a tendency in the writings of media theorists to portray media as ever more autonomous and visible apparatuses that are increasingly decoupled from human agency, a development greeted as salutary by some (Kittler, 1997), or described in apocalyptic terms by others (Baudrillard, 1994; Virilio, 1998).

Recent anthropological work on media and religion in particular has provided evidence for this tension between the highly productive and visible characteristics of newer media technologies and their relative disappearance in the act of mediation. In the contemporary world, there are a wide range of religious practitioners that employ ever more complex media technologies in a bid to gain more direct and "immediate" access to spiritual worlds, God, or other supernatural authorities. For example uses of new audiovisual or sound reproduction technologies by Pentecostal-charismatic Christians in Ghana (Meyer, 2006a,b), or Hindus in India (Rajagopal, 2001; Pinney, 2002), or Muslims in Egypt (Hirschkind, 2006) are geared towards establishing relationships with religious otherworlds that center on an esthetics of what another anthropologist of religion has called the "live and direct" (Engelke, 2007). According to this line of research, such seemingly more "direct" interactions with the supernatural also often privilege the affective and sensual dimensions of religious experience, with the goal of arriving at some state of embodied immediacy with the divine. That is, such religious media practices often aim at making the mediating apparatus vanish as the enabling "in-between" in these religious interactions with an otherworld, however conceived. At the same time, this body of research stresses that such new media practices have produced also new religious subjectivities, and have also created new public spheres or have transformed existing ones with great political effect (see especially Rajagopal, 2001; Hirschkind, 2006; Meyer, 2004). Nevertheless, the obvious mediatic qualities of language in religion have hardly played a role in these approaches that treat media as intrinsic to religion, despite a sizeable body of work on language and religion in linguistic anthropology and related fields in other disciplines (Keane, 2004).

\section{Language and mediation}

How do such double characterizations of media technology relate to the particular medium linguistic anthropologists study, that is language as a medium of socio-cultural worlds? Is the characterization of whatever can function as a medium as oscillating between highly visible, creative power and phenomenological disappearance also of relevance for language as a medium? For students of language this double characterization certainly has a familiar ring. In fact, the opposition between mediatic salience and disappearance was prefigured in 19th and early 20th century debates about language as a medium that finally lead to the Saussurian formulation of the arbitrariness of the linguistic sign (Saussure, 1983). The latter was seen as the point where language becomes a seemingly transparent medium of sense, not because of any presumed glass-like qualities, but because the linguistic sound was considered to be the most "immaterial" of all media, in the sense that its intrinsic qualities and own materiality leave the least imprint on the thoughts and meanings it conveys. In the Western philosophical tradition, one of the main sources of this characterization of the linguistic sound as self-negative and 
meaningless in itself is Hegel (Hegel, 1970 [1830], pp. 270-277, Bodammer, 1968, pp. 47-50), a position further elaborated by Wilhelm von Humboldt, who anticipated the Saussurian notion of the sign as a combination of sound and idea (Ton and Vorstellung) (Humboldt, 1908, pp. 581-583). In contemporary media studies the close parallels between earlier explorations of language as a medium that achieves the greatest "immediacy" of thought and meaning, and the current analysis of contemporary media technologies is rarely remembered, a situation that the German linguist Ludwig Jäger in a Heideggerian register has characterized as the "Sprachvergessenheit" [forgetfulness of language] of contemporary media theory (Jäger, 2000, see also Jäger, 2004; Fehrmann and Linz, 2004; Schneider, 2006).

This insight can also be extended to the parallels between media theorists' concerns about the simultaneous salience and disappearance of media, and work on linguistic relativity in the tradition of Benjamin Lee Whorf. As is well known, Whorf argued that linguistic categories mediate thought in such pervasive ways that the former often leave a shaping imprint on the latter. For him, they influence "habitual" ways of thinking and everyday cultural stereotypes about the world (Whorf, 1956; Lucy, 1992). Whorf introduced the crucial distinction between "overt" and "covert" linguistic categories in the process of linguistic relativity, meaning linguistic categories whose surface forms make them more readily recognizable to its users, and categories that remain largely outside awareness. "Overt" categories are those signaled by an always present formal marker, while such marking only occurs occasionally in the case of "covert" categories (Whorf, 1956, pp. 88-89). Both types of categories influence cognition and the formation of cultural stereotypes, but "covert" categories may do so in an especially pervasive and unconscious manner, as they combine to constitute an underlying web of linkages between linguistic categories which according to Whorf "work together like a unified psychic complex" (Lucy, 1992, p. 30). Michael Silverstein elaborated this distinction further in his comparative analysis of the "limits of awareness," showing how linguistic forms that are maximally segmentable and can be referentially glossed also turn out to be those forms their users are more likely to be aware of, while other linguistic forms and categories tend to be much less accessible to speakers' reflections and stereotypizations (Silverstein, 2001 [1981]). From the perspective of this tradition on the mediality of language, one can thus differentiate elements of language that function as media in highly visible and salient ways from those that are more likely to phenomenologically disappear in the act of mediating thought and cultural stereotypes.

\section{Sound reproduction and Muslim devotional practices in Mauritius}

Keeping these intriguing parallels between language and media technologies in mind, in this paper I investigate how sound reproduction technologies have become part of devotional performances among Mauritian Muslims. These performances, which are known as mahfil-e mawlud, center on the recitation of na't, a genre of praise poetry in honor of the Prophet Muhammad. They are commonly held on the occasion of the birthday of the Prophet, the anniversary of the demise of a saint ('urs) or also auspicious occasions in ordinary peoples' lives, such as weddings, moving into a new home or the passing of important school exams. For many Mauritian Muslims, sound reproduction, as in the listening to audiocassettes, which have now been largely replaced by audio-CDs and $\mathrm{mp} 3$ disks, provides an important means of guidance for performing this genre of poetry appropriately. For them, this media technology thus greatly enhances such performances. Mauritian Muslims are motivated to use electronic sound reproduction because of particular ideas and assumptions they have about this technology, namely that sound reproduction technologies convey past recitations of na't poetry in a most authentic way, especially regarding its performative and stylistic dimensions, and in particular qualities of the voice. In other words, the expectation is that sound reproduction technologies function as a "vanishing," transparent medium and this in particular constitutes its attraction for those engaged in this particular form of religious interaction. In a second step I explore how poetic language functions as a medium of religious interaction and transformation, and compare the linguistic dimension of religious mediation with the perceived transparency of sound reproduction technologies.

Na't is a devotional genre of Urdu language poetry in praise of the Prophet Muhammad that is popular in South Asia and its diasporas, including Mauritius. These are poems that describe the attributes of the Prophet in exuberant terms, as well as places connected with him such as the city of Madina, while expressing deep love and devotion for the Prophet. The recitation of na't, as well as the attentive listening to the poetry is a pious act, because performances of the poetry are transformative events that fill those reciting and listening to the genre with deep love and affection for the Prophet and turn them into better Muslims. In Mauritius, as is the case in South Asia, the cultivation of na't poetry is especially promoted by Muslims following the Ahl-e Sunnat wa Jama'at tradition, a reform movement that originated in 19th century colonial India that is known for its fusion of Sufi traditions with ulema-based Islam. It is also known as the Barelwi tradition after the north Indian birthplace and place of residence of its founder Ahmad Riza Khan Barelwi (1856-1921), a prolific scholar and Sufi saint who was also known as a masterly composer of many na't (Sanyal, 1996). The focus on the Prophet that is so characteristic of na't poetry is profoundly connected to a role of mediator between Muslims and God that followers of the Ahl-e Sunnat ascribe to the Prophet. Reciting na't is a means of interaction with the divine, in which the pious move closer to God because their hearts are filled with love of the Prophet, and in which the latter's presence can literally be summoned by showering praise over him so that he might intercede with God in behalf of the reciters.

Starting in the 1980s, cassette recordings of the genre, and now above all na't on audio-CDs and mp3 disks, have become very popular among Mauritian Muslims. On one hand, this has allowed na't to spread into contexts which it was previously absent, such as when listening to na't alone at home, or while traveling in the car or bus on the way to work. On the other hand, sound reproduction techniques have come to take an important role in preparing for the mahfil-e mawlud as the 
established context of na't performance. This is because many Mauritian Muslims regard recordings of performances of skilled reciters (na't khwan) from India and Pakistan, and now also of Mauritian na't khwan trained by the former as authoritative sources of emulation for mahfil-e mawlud (Eisenlohr, 2006a, 2010). Not only in matters of textual authenticity, but especially when it comes to the appropriate performative style, they take sound reproduction to be an important means of guidance ensuring that na't performances unfold in a correct manner. This latter point is crucial for several reasons.

First, na't is a delicate and controversial genre among Muslims in Mauritius and in the wider South Asian World, because of the danger of taking the praise of the Prophet too far, and portraying him as a God-like figure. Followers of rival and more purist schools in South Asian Islam, such as those of the famous school of Deoband have traditionally criticized the cultivation of na't, and also other devotional practices centered on the Prophet that followers of the Ahl-e Sunnat engage in exactly on these grounds. They consider the practice as evidence of what they view as an exaggerated focus on the Prophet that comes dangerously close to undermining the unity of God. And as many followers of the Ahl-e Sunnat are ready to admit, the composition of na't is a difficult task that requires keeping a delicate balance between high praise of the Prophet and the preservation of the unity of God. Therefore, it is very important that the poems can be traced back to an authoritative source, ideally the authorship of a well-known scholar-saint, such as Ahmad Riza Khan Barelwi. The authenticity and "correctness" of the text is thus crucial for this particular practice of intercession and pious transformation to succeed.

Second, the effect of reciting na't is also heavily dependent on the appropriate performative style. This entails a style of recitation that is emotional, but still exhibits enough moderation in speed and rhythm, being balanced by decorum and absence of agitation. In particular, the desired manner of recitation should not remind one of or otherwise cross over into entertainment genres, such as Hindi films songs. Even though the expected style of recitation can be highly melodious, it is normatively set off from singing and music, and there is also no use of musical instruments. Mauritius is an environment where Bollywood entertainment is very pervasive. Hindi film songs and music have a major impact on the esthetic sensibilities of reciting Urdu poetry, but for pious Muslims they often have unwelcome moral associations. In addition, for many of those cultivating na't in Mauritius, the fact that there are a few Hindi films that have featured na't recitals makes the maintenance of a strong boundary between this devotional genre and forms of Bollywood entertainment even more important. That is, the successful recitation of na't in a mahfil-e mawlud is a performative achievement that is at continuous risk for failure. Both the "correctness" of the poetic text as well as the appropriateness of the style performance is essential to the effectiveness of na't as a technique of intercession and accumulation of spiritual merit.

As the performative dimension cannot be effectively mediated by print, Mauritian Muslims treat sound reproduction as eminently suited as a means of guidance for organizing and preparing for a mahfil-e mawlud, especially in a situation as in Mauritius where there are only few accomplished na't khwan who can serve as examples to be emulated. This is one of the major reasons why those preparing a mahfil-e mawlud listen to recordings of na't poetry to make a "program," as my interlocutors say, selecting particular na't to be performed, while refreshing their esthetic sense of how the genre should be recited. For their users, such recordings provide a "direct" connection to events where na't is recited in the authoritative style. They represent a medium that minimizes its own "noise" in conveying the presence of authoritative na't recitation, and thus supports the efforts by the participants in a mahfil-e mawlud to bring about the presence of the Prophet and the blessings attached to it. In other words, compared to other forms of media, such as the written compilations of na't that continue to be used in Mauritius (Edun, 2006), sound reproduction here functions as a more transparent medium that enables a sense of relative immediacy with sources of spiritual authority. It is important to realize that these capabilities that Mauritian Muslims cultivating na't often ascribe to sound reproduction technology depend on particular ideas and assumptions about this technology, here a particular media ideology that is informed by a religious tradition of interaction with God taking voice to be the chief site of divine presence. The chief paradigm of what has been described as an established tradition of "logocentric recitationalism" (Messick, 1993, pp. 21-25) is that reciting scripture summons the presence of the divine. But the importance of recitation has also influenced the way in which Mauritian Muslims approach other kinds of devotional discourse, such as na't poetry. ${ }^{1}$ Also, it is striking how the deployment of newer media technologies to establish a seemingly more "immediate" relationship with the divine turns out to be a source of authenticity and authority. As I have pointed out, this importance of sound reproduction technologies is above all related to what those Mauritian Muslims cultivating na't view as their beneficial effects not only on the process of reliably transmitting the "correct" text, but also the appropriate ways and styles of performing the poetry. Here sound reproduction technologies appear to do so in a more "direct" way than writing, as for example compared with the written instructions on how to recite na't and the practical advice on how to prepare for and hold a mahfil-e mawlud that could be found in printed compilations of na't, such as the popular manual and na't collection milad-e akbar which was also widely used in Mauritius. To sum up, the role of sound reproduction thus chiefly lies in establishing a seemingly more immediate link between Mauritian Muslims who perform and listen to na't as part of a wider tradition in South Asian Islam that places particular emphasis on devotion to the Prophet, and authoritative examples of correct recitational practice, whose emulation will in turn enable those following these examples to enter in a more immediate relationship with the Prophet, and ultimately, God.

It is important to realize that claims for more a "direct" access to religious sources of authority often also involve claims to authority in other social and political fields, which recalls what has recently become known as a "politics of immediation" among anthropologists of media (Mazzarella, 2006, see also Allen, 2009 and Eisenlohr, 2009). Mauritian Muslims who follow

\footnotetext{
${ }^{1}$ See Eisenlohr (2006a, 2010) for a more detailed discussion of “logocentric recitationalism” in relation to Mauritian na't recitals.
} 
the Barelwi tradition of South Asian Islam draw on such media effects of a more "live and direct" connection to the supernatural in order to defend their controversial devotional practices, to uphold the legitimacy of this tradition against more purist detractors, and to ultimately cast themselves as the representatives of "true Islam" in Mauritius (Eisenlohr, 2006a). This all is the more important because as is the case throughout the South Asian world the followers of the Barelwi tradition in Mauritius engage in severe competition with those following the more purist school of Deoband, and more recently also Salafi groups. Deobandis and Salafis condemn devotional practices strongly focused on the figure of the Prophet such as na't recitations as undermining the unity of God, and more generally charge Barelwis with having introduced additional and illegitimate innovations that can be attributed to their Indian cultural environment.

In addition, the question of who can claim the most "direct" and authentic connection to God, thus representing "true Islam" also has a significant local political dimension, because Mauritian postcolonial politics of nation-building and citizenship privilege the cultivation of officially recognized diasporic "ancestral cultures" as signs of membership in the nation. ${ }^{2}$ These "ancestral cultures" in turn principally center on religious traditions, and for Muslims as one of the officially recognized "communities" of Mauritius Islam represents their "ancestral culture." The government treats the Barelwi leadership as the established representatives of Islam in Mauritius, which is also aided by the fact that the country's most prominent mosque, the Jummah Mosque in the capital Port Louis has traditionally been under the control of the Kutchi Memons, the Gujarati trader community who established Barelwi institutions in Mauritius (Eisenlohr, 2006b). Therefore, those who can claim authentic Islam in Mauritius can also claim to represent Muslims vis-à-vis the Mauritian state and be assured of inclusion in the Mauritian nation.

\section{Medialities compared}

How does the sense of relative spiritual immediacy that Mauritian Muslims associate with the use of sound reproduction technologies in the cultivation of na't compare with the linguistic dimensions of this form of religious mediation? At first sight, the association of spiritual closeness and relative immediacy with a disappearing medium is counterintuitive in the case of na't poetry. Mauritian Muslims appreciate this kind of poetry whose recitation in the appropriate way brings about spiritual transformation -imbuing the reciter and those attentively listening with love of the Prophet- exactly for its salient formal and esthetic properties, its crafted beauty and artifice, and its extensive metric, phonetic and semantic parallelisms. In other words, since this kind of poetry achieves its desired performative effects through the foregrounding of its formal properties (compare Jacobson, 1960), it appears to be the very opposite of a phenomenologically transparent and vanishing medium.

Let us recall the linguistic tradition that attaches great importance to the distinction between arbitrary and motivated linguistic signs, following the idea that language can only be a perfect medium of sense if the linguistic sound ceases to have an impact of its own in the constitution of sense. Following this position, one would have to distinguish between linguistic elements that are fully arbitrary in a Saussurian sense, thus constituting the "transparent" elements of the linguistic medium, and those elements that lack such a relationship, such as found in the indexical and above all iconic dimensions of linguistic signification. Similarly, following Whorf's distinction between "overt" and "covert" categories, the tradition of linguistic relativity has differentiated between linguistic elements that mediate thought in a manner that eludes awareness, and those parts of language that do so in a more salient manner (Silverstein, 2001 [1981]).

In my view, however, the specific effects of religious mediation that the performance of na't poetry accomplishes cannot be found in particular linguistic elements, that is there is no clear distinction between parts of language that mediate interaction with the divine in a more "transparent" manner, and others that supposedly play a lesser role in doing so. The effect of a relative phenomenological minimization of the poetry as a medium of religious interaction and transformation lies much more in the faithfulness to presupposed generic conventions and norms of appropriateness in performance. If there is any sense in my example in which language can play the role of a medium that minimizes its own visibility and largely eludes phenomenological awareness it has to be looked for on these levels of linguistic interaction. An array of generic and textual conventions, as well as notions of appropriate recitational style and qualities of voice informs na't performances. In other words, as with many other performative events, and certainly poetry recitals, there is a dense web of presupposed indexicality (Silverstein, 1995 [1976]) surrounding such performances. Rather than pointing to specific linguistic forms as elements of a phenomenologically "vanishing" medium of religious interaction, the relative visibility and invisibility of language as a medium resembles much more an aggregate state in flux that changes with the particularities of performance and the situational context of this interaction with the divine that those Mauritian Muslims who are cultivating na't strive for.

Ludwig Jäger has recently made a similar point highlighting the parallels between the workings of media technologies and language, in which he argues that linguistic interaction involves a constant oscillation between what he calls "transcriptive" interference (Störung ${ }^{t}$ ) and apparent transparency (Transparenz). Drawing on Derrida's reflections on the "iterability of language" (Derrida, 1991), for Jäger "interference" is not necessarily a matter of linguistic miscommunication demanding repair, but a "transcriptive" process inherent in language use that involves the routine reflection on, and rewriting and recasting of

\footnotetext{
2 According to the constitution Mauritians are divided into four principal "communities": Hindus (52\%), Muslims (17\%), Sino-Mauritians (2\%) and the General Population (29\%). The General Population comprises all Mauritians who do not belong to the three aforementioned categories, de facto these are Creoles and Franco-Mauritians, who are Christians, overwhelmingly Catholics. With the exception of the small and multireligious Sino-Mauritian community, there is a striking overlap between the boundaries between the officially recognized ethnic communities and religious boundaries in Mauritius.
} 
what has just been said (Jäger, 2004). While I am inspired by his valuable insight that productive "interference" and "transparence" are not intrinsic properties of particular linguistic forms but situationally shifting states of language, his argument remains within the framework of intentionalist semantics, in which the yardstick for evaluating the collaborative and "transcriptive" re-writings and repairs of utterances in conversations is ultimately the working out of inner intentions of subjects (Jäger, 2004, p. 46). It is through the laboring towards correspondence of utterance with speaker intentions that "transparency" can at least be momentarily re-established. In line with linguistic anthropological critiques of intentionalist theories of meaning (Hill and Irvine, 1993; Duranti, 2001), I propose to extend Jäger's argument by shifting away from speaker intentions to contextual conditions and indexicality as the main site where such fleeting instances of "transparency" in language can be achieved. The linguistic medium enters a state of salient "interference" in those moments where for at least some participants in the interaction at hand there is a marked departure from presupposed contextual and co-textual norms and cues. Conversely, the salience of language as a medium decreases at those times when the interaction unfolds along the lines of such presupposed indexicality.

Thus in my example, the mediality of language consists in the oscillation between a contextual state in which the performance of na't unfolds in culturally and situationally expected ways, and moments when this is not the case. This movement occurs not only in relation to the widely shared norms and expectations that informs the sequences and correlations between the linguistic signs of the poetic text. Just as important is the complex web of expected co-occurrences of these linguistic signs with other non-linguistic significant phenomena, which include the participants' social identities and roles, their spatial positions, the embodied qualities of voice, as well as of course the kind and quality of the setting of the performance. As long as performances unfold in presupposed manners along all these multiple dimensions, the linguistic medium draws minimal attention in its role as the enabling mediator of a relationship between Muslims and the Prophet, and ultimately God.

Na't recitations, however, are not just a preexisting type of religious practice and interaction, they are always a delicate performative achievement subject to failures on multiple levels. Marked departures from the web of presupposed indexicality that guide such performances can instantaneously change the perceived "transparency" of the linguistic medium. For example, a recitational style that blends with the esthetics and generic conventions of Hindi film songs, suddenly disturbs the smooth functioning of the linguistic medium and re-focuses the participants' attention on a perceived mismatch between qualities of voice, melody, the kind and purpose of the event, and the poetic text, and thus also on the linguistic medium itself. In comparison with uses of media technologies, in functional terms this is the equivalent of a dropped call, a computer network problem or a scratch on a record or DVD, dramatically increasing the interfering "noise" of the medium itself and thus almost forcibly drawing attention to the media technology involved in a particular interaction. This state will persist until the performance is "repaired" by reverting to established norms and expectations shaping the performance, or until these norms and expectations themselves undergo change. A movement back and forth between these performative states, between the violation of presupposed norms and expectations, their reassertion, and back, is characteristic of the actual unfolding of na't performances. This also goes along with the oscillation of the linguistic medium from high visibility to phenomenological minimalization, and back. In other words, the mediality of language is a process that knows different states or phases and moves back and forth between them.

Na't performances also illustrate how important it is to keep the perspective- bound quality of the mediality of language in mind. Even in the context of the same performance, poetic language that may seem to be a smoothly functioning and therefore momentarily unremarkable medium for some, may be evaluated according to different ideas and norms of appropriateness by others. For example, crossovers into the generic conventions of Hindi film songs meet strong disapproval by some Mauritian Muslims, while others express their tolerance of such stylistic modifications.

Until the 1980s it was commonplace to listen to Indian na't reciters such as the late Mohammad Rafi (1924-1980), who was better known as the most famous playback singer of the Hindi cinema at the time, and who blended his recitational style with the musical esthetics of the Hindi film. Ever since, a much more purist attitude has gained ground among Mauritian Muslims who cultivate the practice of na't. As one young na't khwan, an Urdu teacher his early thirties who lives in a village in the north of Mauritius told me, it is not just important that na't poetry can be traced to the authorship of famous saintteachers, such as for example the Hada'iq-e bakhshish, Ahmad Riza Khan Barelwi's collection of na't poetry (Khan Barelwi, n.d.). According to him, one should also not recite the poetry in a "film style" (filmi taraz), because if one combines the poetry with film style recitation, the listeners' minds will wander away from pious devotion to the Prophet to the morally problematic sensuality of the film and its narrative. As the Urdu teacher and na't khwan put it, the emotionally touching and correct style "from the heart" (dil se) that nevertheless avoids the agitation and excess of the film style needs to be carefully invited, or literally "be seated" into the na't (na't men taraz baithana) in order for the performance to be a success.

But not everyone shares such views. Another na't khwan, a tailor in his 50s in a village in the east saw no need at all to draw a boundary between the esthetics of film songs, musical entertainment, and na't recital at a mahfil-e mawlud. He recites na't in a way he describes as "emotional and rhythmic" and that resembles filmi taraz. He even argued that reciting na't accompanied with a daf, a drum that resembles the ravan, the emblematic instrument of Mauritian séga music that Mauritians treat as a cultural emblem of the Creole community of largely African descent is not barred ( $p a$ empese), and that he draws a lot of inspiration from the qawwali devotional Sufi music genre for his na't recitals. I found a spectrum of views resembling the contrasts between these two na't khwans' takes on the relations between the world of film music and na't recitals also among Mauritian Muslims who were only accustomed to listening to na't but not performing it in a lead role. While the purist stance insisting on a marked separation between na't performance and the realm of "music" and 
the world of film songs in particular is clearly on the rise, there is considerable diversity of esthetic sensibilities among a wider Mauritian Muslim public cultivating na't.

Thus, what appears to be a disruption of generic conventions that are vital to the success of the na't performance, is unproblematic for others. The language of the na't genre is thus simultaneously transparent and obstinate. This applies to both the regular oscillation between relative transparence and interference that characterizes the functioning of language in performance, and divergences in the perceived state of the linguistic medium for different participants at the same moment as the performance unfolds.

\section{Conclusion}

To conclude, the interaction between sound reproduction as a media technology and language as a medium of interaction with the divine in the context of performing na't poetry can be characterized as follows. For the cultivation of na't, Mauritian Muslims treat sound reproduction as a support and safeguard of presupposed performative styles and esthetic norms. Informed by the particular ideas and expectations Mauritian Muslims bring to bear on this media technology, cassettes, and now above all audio-CDs and Mp3 disks support what one could describe as the "vanishing" aspects of the linguistic medium. Such uses of sound reproduction technology in devotional settings thus illustrate how a particular esthetics of authenticity centered on the "live-direct" that emerges from uses of contemporary media technology interacts with discursive regimes of authenticity. Under the circumstances I have discussed, the intersection of sound reproduction and language as two different media exhibits an intriguing paradox. Even though na't is a form of devotion in which markedly poetic language is the medium of interaction with the Prophet, and ultimately God, sound reproduction technology enhances the authenticity and authority attached to such performances precisely by drawing the listeners' attention away from language as a mediator of the divine.

\section{Acknowledgements}

An earlier version of this article was presented at the 2009 Annual Meeting of the American Anthropological Association in Philadelphia. I thank Dominic Boyer and Paul Manning for their very helpful discussant comments. In particular, I would like to thank Asif Agha for his stimulating orienting work in convening this issue and for inviting me to a series of discussions on linguistic anthropology and media at the University of Pennsylvania which greatly helped me in developing the arguments in this paper.

\section{References}

Agha, A., 2007. Recombinant selves in mass mediated spacetime. Language \& Communication 27, 320-335.

Allen, L., 2009. Martyr bodies in the media: human rights, aesthetics, and the politics of immediation in the Palestinian intifada. American Ethnologist 36 (1), $161-180$

Barker, J., 2008. Playing with publics: technology, talk, and sociability in Indonesia. Language \& Communication 28, $127-142$.

Baudrillard, J., 1994. Simulacra and Simulation. University of Michigan Press, Ann Arbor.

Bodammer, T., 1968. Hegels Deutung der Sprache. Hamburg, Felix Meiner.

Bolter, J.D., Grusin, R., 1999. Remediation: Understanding New Media. MIT Press, Cambridge.

Derrida, J., 1991. Signature, event context. In: Kamuf, P. (Ed.), A Derrida Reader: Behind the Blinds. Columbia University Press, New York.

Duranti, A., 2001. Intentionality. In: Duranti, A. (Ed.), Key Terms in Language and Culture. Blackwell, Oxford, pp. 129-131.

Edun, E.H., 2006. Urdu Studies in Mauritius. Star Publications, New Delhi.

Eisenlohr, P., 2006a. As Makkah is sweet and beloved, so is Madina: Islam, devotional genres and electronic mediation in Mauritius. American Ethnologist 33 (2), 230-245.

Eisenlohr, P., 2006b. The politics of diaspora and the morality of secularism: Muslim identities and Islamic authority in Mauritius. Journal of the Royal Anthropological Institute (N.S.) 12(2), 395-412.

Eisenlohr, P., 2009. Technologies of the spirit: devotional Islam, sound reproduction, and the dialectics of mediation and immediacy in Mauritius. Anthropological Theory 9 (3), 273-296.

Eisenlohr, P., 2010. Materialities of entextualization: the domestication of sound reproduction in Mauritian Muslim devotional practices. Journal of Linguistic Anthropology 20 (2), 314-333.

Engelke, M., 2007. A Problem of Presence: Beyond Scripture in an African Church. University of California Press, Berkeley.

Fehrmann, G., Linz, E., 2004. Resistenz und Transparenz der Zeichen. Der verdeckte Mentalismus in der Sprach- und Medientheorie. In: Fohrmann, J., Schüttpelz, E. (Eds.), Die Kommunikation der Medien. Niemeyer, Tübingen, pp. 81-104.

Goebel, Z., 2008. Enregistering, authorizing, and denaturalizing identity in Indonesia. Journal of Linguistic Anthropology 18 (1), $46-61$.

Harvey, D., 1989. The Condition of Postmodernity: An Inquiry into the Origins of Cultural Change. Blackwell, New York.

Hegel, G.W.F., 1970 [1830]. Werke 10. Enzyklopädie der Philosophischen Wissenschaften III. Frankfurt, Suhrkamp.

Hill, J.H., Irvine, J.T. (Eds.), 1993. Responsibility and Evidence in Oral Discourse. Cambridge University Press, Cambridge.

Hirschkind, C., 2006. The Ethical Soundscape: Cassette Sermons and Islamic Counterpublics. Columbia University Press, New York.

Hoffmann, S., 2002. Geschichte des Medienbegriffs. Felix Meiner, Hamburg.

von Humboldt, W., 1908. Über Denken und Sprechen. In: Preussische Akademie der Wissenschaften (Ed.), Gesammelte Schriften VII.2. B. Behr's Verlag, Berlin, pp. 581-583.

Jacobson, R., 1960. Closing statement: linguistics and poetics. In: Sebeok, T.A. (Ed.), Style in Language. MIT Press, Cambridge, MA, pp. $350-377$.

Jäger, L., 2000. Die Sprachvergessenheit der Medientheorie. Ein Plädoyer für das Medium Sprache. In: Kallmeyer, W. (Ed.), Sprache und neue Medien. de Gruyter, Berlin/New York, pp. 9-30.

Jäger, L., 2004. Störung und Transparenz. Skizze zur performativen Logik des Medialen. In: Krämer, S. (Ed.), Performativität und Medialität. Wilhelm Fink, München, pp. 35-73.

Jones, G., Schieffelin, B., 2009. Enquoting voices, accomplishing talk: uses of be + like in Instant Messaging. Language \& Communication 29 (1), 77-113.

Keane, W., 2004. Language and Religion. In: Duranti, A. (Ed.), A Companion to Linguistic Anthropology. Blackwell, Malden, MA, pp. 431-448. 
Khan Barelwi, A.R., n.d. Hada'iq-e bakhshish. Raza Academy, Mumbai.

Kittler, F., 1997. In: Johnston, J. (Ed.), Literature, Media, Information Systems. G+B Arts International, Amsterdam.

Lucy, J., 1992. Language Diversity and Thought: A Reformulation of the Linguistic Relativity Hypothesis. Cambridge University Press, Cambridge.

Mazzarella, W., 2006. Internet X-Ray: E-Governance, Transparency, and the Politics of Immediation in India. Public Culture 18 (3), $473-505$.

McLuhan, M., 1964. Understanding Media. New York/Toronto, McGraw-Hill.

Messick, B., 1993. The Calligraphic State: Textual Domination and History in a Muslim Society. University of California Press, Berkeley.

Meyer, B., 2004. "Praise the Lord”: popular cinema and pentecostalite style in Ghana's new public sphere. American Ethnologist 31 (1), 92-110.

Meyer, B., 2006a. Religious revelation, secrecy, and the limits of visual representation. Anthropological Theory 6 (4), $431-453$.

Meyer, B., 2006b. Impossible representations: pentecostalism, vision, and video technology in Ghana. In: Meyer, B., Moors, A. (Eds.), Religion, Media, and the Public Sphere. Indiana University Press, Bloomington, pp. 290-312.

Pinney, C., 2002. The Indian work of art in the age of mechanical reproduction: or, what happens when peasants "get hold" of images. In: Ginsburg, F.D., Abu-Lughod, L., Larkin, B. (Eds.), Media Worlds. University of California Press, Berkeley, pp. 355-369.

Rajagopal, A., 2001. Politics after Television: Hindu Nationalism and the Reshaping of the Public in India. Cambridge University Press, Cambridge.

Sanyal, U., 1996. Devotional Islam and Politics in British India: Ahmad Riza Khan Barelwi and His Movement (1870-1920). Oxford University Press, Oxford. de Saussure, F., 1983. Course in General Linguistics. Trans. Roy Harris. Open Court Press, La Salle, IL.

Schneider, J.G., 2006. Language and mediality: on the medial status of 'everyday language'. Language \& Communication 26, $331-342$.

Silverstein, M., 1995. Shifters, linguistic categories, and cultural description. In: Blount, B. (Ed.), Language, Culture, and Society: A Book of Readings. Waveland Press, Prospect Heights, pp. 187-221 (1976).

Silverstein, M., 2001. The limits of awareness. In: Duranti, A. (Ed.), Linguistic Anthropology: A Reader. Blackwell, Malden, pp. 382-401 (1981).

Spitulnik, D., 1996. The social circulation of media discourse and the mediation of communities. Journal of Linguistic Anthropology 6 (2), $161-187$.

Sterne, J., 2003. The Audible Past: Cultural Origins of Sound Reproduction. Duke University Press, Durham.

Tomlinson, J., 1999. Globalization and Culture. University of Chicago Press, Chicago.

Virilio, P., 1998. In: Der Derian, J. (Ed.), The Virilio Reader. Blackwell, Malden, Mass./Oxford.

Whorf, B., 1956. Language, Thought, and Reality. Cambridge, MA, MIT Press. 